\title{
El meu nom. Un treball d'identitat des de la mirada de l'educació sistèmica multidimensional
}

\author{
Mercè Pena Laguna \\ Escola Antoni Vilanova de Falset \\ mpena9@xtec.cat
}

Resum:

Abstract:

Sense arrels no hi ha ales...

Without roots there aren't wings...

(Bertorld Ulsamer)

(Bertorld Ulsamer)

Aquest treball és una proposta d'activitats d'educació primària, preparades $i$ aplicades en aquesta experiència en alumnes de cicle inicial i mitjà de dues escoles diferents del Baix Camp i el Priorat. El projecte es va dur a terme durant quinze sessions que tenien una durada de tot un matí o tarda. Durant el conjunt de pràctiques englobades en el projecte "El meu nom" es van treballant les diverses competències educatives: personals, interpersonals, de conviure i habitar el món, comunicatives... A més, s'estableix un pont important de col-laboració amb les famílies per tal d'enfortir la cohesió de grup, treballar la identitat i les emocions i aprofundir en totes les dimensions de l'educació sistèmica multidimensional.

Paraules clau: educació sistèmica; emocions; família; arbre genealogic; identitat; tribu 


\section{Objectius}

El principal objectiu d'aquesta proposta és treballar el concepte d'identitat per saber on sóc, qui sóc i d'on vinc i enfortir el sentiment de pertinença del grup mostrant i aprenent a mirar amb respecte els diferents orígens dels companys.

Es pretén crear un espai que aculli, per poder solucionar conflictes des d'una mirada sistèmica, introduint un ordre, una jerarquia de gran a petit, un equilibri entre els alumnes, i potenciar la comprensió de les individualitats com a regal i del concepte de grup i tribu com a potencial creatiu.

\section{Contextualització}

Actualment sóc tutora de cicle inicial a l'escola pública Antoni Vilanova. Lexperiència que presento es va dur a terme a la classe de segon de primària, al moment d'assemblea del matí.

\section{Descripció de l'experiència}

El plantejament d'aquesta proposta està fonamentat en les aportacions de diferents autors: Hellinger (2008), Traveset (2007, 2014), La Moneda (2010), Gardner (2011), Cordero (2012), Traveset i Parellada $(2014 a, 2014 b)$.

Seguidament descriuré l'experiència, la metodologia emprada i les activitats proposades.

Asseguts a l'espai de l'assemblea, inici del nostre espai per compartir, faig la meva proposta: coneixeu els inuits? Un poble savi, que viu en absoluta harmonia amb el seu entorn, amb un equilibri fantàstic d'adaptació, i amb un concepte de comunitat i saviesa (Bailón Trueba, 2015).

Els inuits creuen que quan un membre de la tribu abandona la vida, una part de l'esperit va de traspàs a altres regnes, i una altra part es queda amb la tribu, es transmet en els poders del nom.

Quan neix un nadó inuit se li posa el nom de l'última persona de la tribu que ha mort (els noms inuits tenen doble gènere), és una manera d'honrar els avantpassats i de mantenir part de l'esperit de la tribu. Dins el nom de cada inuit hi ha amagats els dons i talents dels seus avantpassats.

Us convido a descobrir una mica més qui som, els talents dels nostres noms; a descobrir, d'una forma creativa i partícip, el poder de la nostra comunitat, de la classe, de la nostra petita tribu.

Dins l'assemblea de l'aula s'inicia un treball de coneixença i aprofundiment entre els companys mitjançant el diàleg, exposant l'art de fer preguntes per acompanyar el procés d'autoconeixement de cadascú. Motivant els alumnes a ser els propis detectius i investigadors, s'inicia un treball, un viatge, acompanyat de la família, que es va registrant en una llibreta personal que fa el recorregut de casa a l'escola per establir el pont de comunicació i descoberta.

\section{Primera acció}

Qui sóc jo? La meva identitat comença pel meu nom i les preguntes que ens qüestionem a partir d'aquest.

Per què tinc aquest nom? Quin significat té? Qui el va escollir? Es repeteix el meu nom en la meva família?

Activitats proposades:

Comença la investigació buscant el significat del nom utilitzant la xarxa. El treball de casa amb els familiars serà saber com van escollir el meu nom, si es repeteix i és tradició familiar, si té un significat especial per a la persona que el va escollir.

En tots els casos, totes les devolucions són especials, úniques i meravelloses i seran tractades amb veritable respecte i admiració, honrant cada nom.

Reflexions sobre aquesta proposta:

Origen i significat de noms propis: el nom de cada persona se solia escollir per transmetre certes característiques o poders implicats en aquest. Antigament cada nom tenia un significat especial que amb l'ús i l'evolució del llenguatge s'ha anat perdent, i actualment moltes persones no coneixen l'origen i significat del seu nom. Igual que en moltes cultures indígenes contemporànies, els noms propis també en el seu origen tenen un significat especial que es transmet a qui els porten.

Investiguem a casa per què ens han posat aquest nom. Treballem amb els pares: quina va ser la raó per la qual van escollir el nostre nom? 
Qui el va escollir? Hi ha algú més de la família que es digui així o que s'hi hauria d'haver dit? Si és un nom que en la nostra família es va repetint, podem buscar quines persones el van portar i quin lloc tenen en la família (genograma).

Els altres noms: de vegades, a casa no ens diuen pel nostre nom, sorgeixen diminutius, adjectius, noms nous, més emocionals. Pot ser que casa nostra també tingui un nom i un sobrenom: som de ca la..., ens diuen...

\section{Segona acció}

El símbol i el nom secret: de tots els significats trobats, ens deixem sentir amb la paraula que més ens defineix. De les diverses definicions, agafem i fem nostra la que en aquests moments millor escau a allò que sentim, al moment en què ens trobem (dimensió intrapsíquica).

Activitats proposades:

a) Dibuixar un símbol que identifiqui el meu nom

b) Retallar de diferents formats les lletres que configuren el meu nom secret

c) Prendre el significat del meu nom

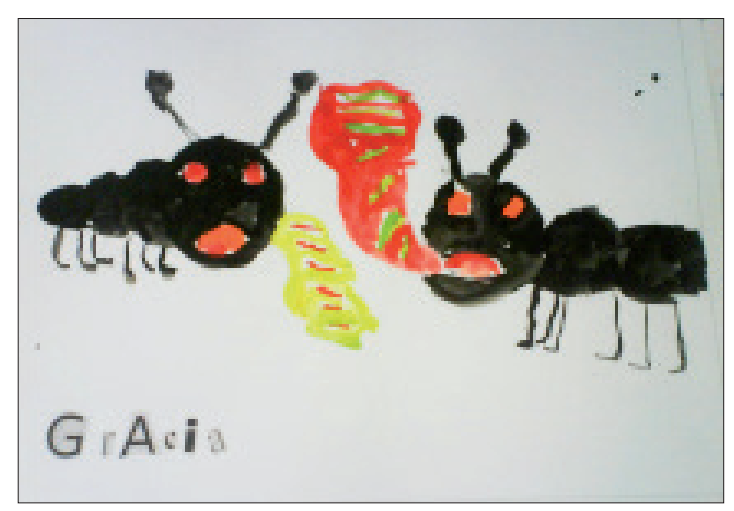

Reflexions sobre aquesta proposta:

La creativitat ens envaeix, deixem que sorgeixin les imatges que podem sentir en el nostre nom, que poden il.lustrar el nostre significat escollit: farem un dibuix relatiu al significat del nostre nom, crearem un paisatge, un espai, on deixar que el nostre nom transiti.

Utilitzarem pintures i cavallet. Qualsevol tècnica és vàlida. Cuidem l'espai i el material. En aquesta activitat cerquem un moment de creació artística i d’exploració.
Un cop configurada la producció creativa amb el significat que ens evoca, busquem en revistes tipus de lletra diferents per compondre el nostre nom.

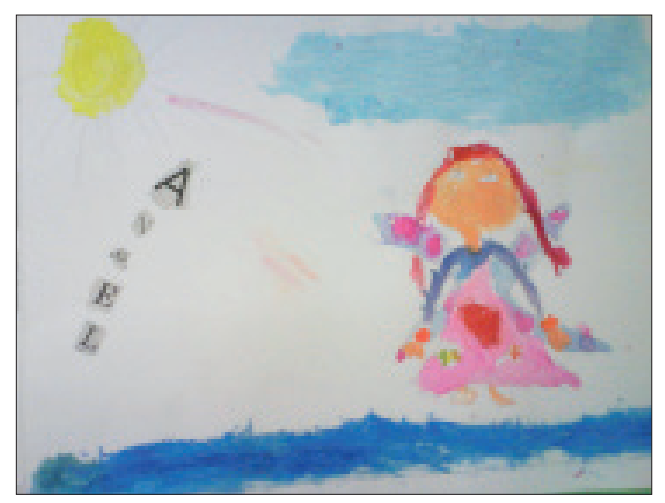

\section{Tercera acció}

Els rituals: un cop pres el nostre nom, carreguem d'emoció el ritual que l'acompanya. Lapoderem amb unes accions.

Activitats proposades:

a) Dansa d'agraïment: amb una música dels Balcans fem una senzilla dansa que s'inicia amb el joc de mans (que ajuntant-se i saludant fan una pinya) i acaba amb la inclinació i l'agraïment.

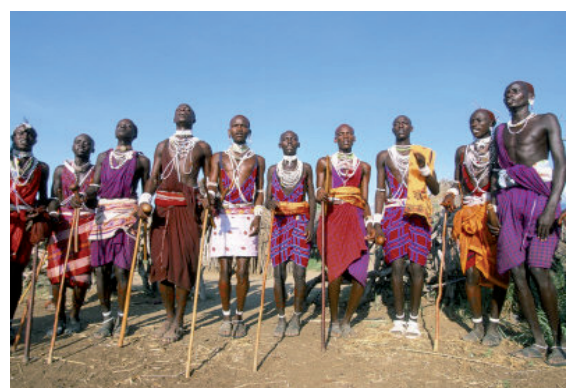

b) Cercle del nom: com un equip, diem en ordre de gran a petit el nostre nom secret, ajuntant les mans en un cercle, fent una pinya.

c) La cançó del nom: visualització del conte "La cançó de les persones" (Phanem).

Reflexions sobre aquesta proposta:

Un ritual són una sèrie d'accions, realitzades principalment pel seu valor simbòlic, prescrites per una religió o per les tradicions d'una comunitat. El terme ritu prové del llatí ritus. 
A través dels llaços del grup neix la dansa. La dansa sorgeix de la necessitat de l'home d'expressar els seus desitjos i les seves pors, és una cosa inherent a l'ésser humà. Les emocions més bàsiques s'exterioritzen a través del moviment, és el reflex de l'essència mateixa de la persona, que utilitza el seu propi cos per comunicar-se, per entrar en contacte amb el món que l'envolta (Rodrigo de la Casa, 2012).

Amb la dansa, neixen també els instruments de música; possiblement la veu humana va ser el primer, després van venir la percussió, l'aire, etc.

Actualment, en el món modern, com un halo espiritual ancestral, la dansa i la música són els llaços que més uneixen la humanitat sense distincions de races i pobles.

\section{Quarta acció}

Les emocions en el món intrauterí: l’any en el qual estàvem dins de l'úter matern, impregnar la gestació. El que va succeir l'any en què vam néixer.

Activitats proposades:

a) Seleccionar les notícies importants que van succeir l'any del nostre naixement.

b) Fer una exposició d’aquestes notícies als companys.

c) Entre tots, realitzar un mural.
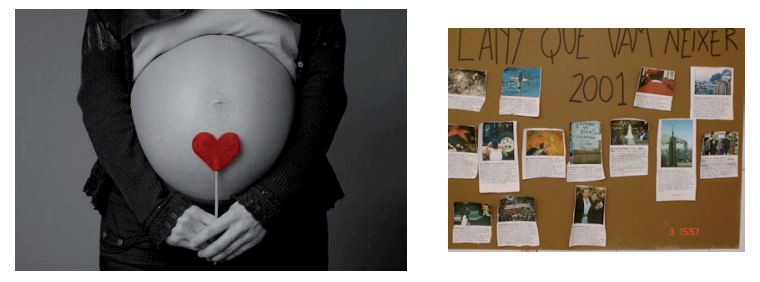

Reflexions sobre aquesta proposta:

Tot el que va succeir mentre érem en el procés de gestació, el que van viure els nostres pares, la família, el que va succeir en la nostra societat i entorn, influirà en el benestar de la nostra mare i en la nostra memòria.

En les cultures orientals i antigues, els astres i els planetes marcaven una manera de fer en el nostre naixement.

Lastrologia, els horòscops orientals o el coneixement de treballs tan interessants com l'enneagrama amplien la mirada de l'arribada a aquest món. En diferents cultures cada any té un significat, un símbol. Anem descobrint els horòscops.

\section{La meva arribada al món}

Cada tipus de naixement condiciona el desenvolupament de les persones, els vincles.

Activitats proposades:

Investigar com va ser el nostre naixement: on va ser? Qui acompanyava la mama? Qui em va agafar primer? Quin temps feia? Quins records tenen la família d’aquell moment?

\section{Cinquena acció}

Quin lloc ocupo en la meva família?

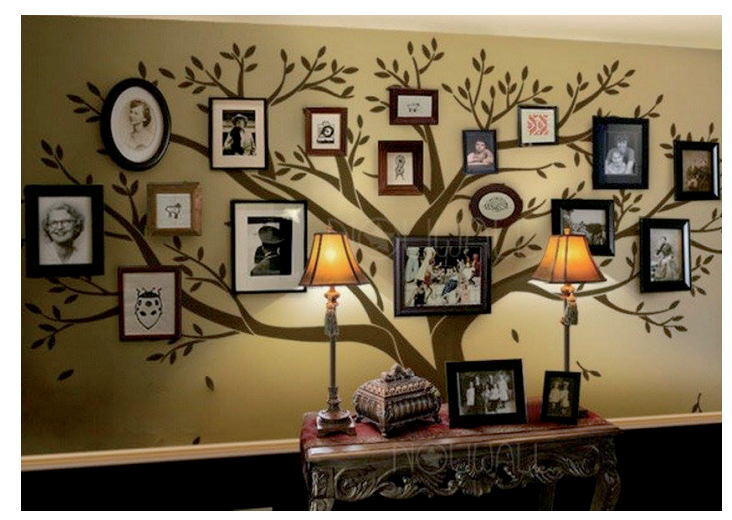

Activitat proposada:

Investigar quin lloc ocupo en la família, entre els germans, entre els néts, entre els cosins (introducció de l'arbre genealògic).

Reflexions sobre aquesta proposta:

Malgrat les crítiques rebudes, la teoria dels camps mòrfics de Rupert Sheldrake ens aporta una informació interessant. És el bioquímic britànic que va postular la hipòtesi més revolucionària de la biologia contemporània: la de la ressonància mòrfica.

Les ments de tots els individus d'una espècie - inclòs l'home - es troben unides i formen part d'un mateix camp mental planetari. Aquest camp mental - al qual va denominar morfogenètic - afecta les ments dels individus, i les ments d'aquests també afectarien el camp. Com afirma Sheldrake (2009), "cada espècie animal, vegetal o mineral posseeix una memòria collectiva a la 
qual contribueixen tots els membres de l'espècie i a la qual conformen".

Aquests camps morfogenètics contenen informació recopilada de tota la història i l'evolució passada, alguna cosa a la manera de la memòria racial de Freud, l'inconscient col-lectiu de Jung o el circuit neurogenètic de Timothy Leary. La ressonància mòrfica, el principi de memòria collectiva, es pot aplicar a l'estudi de l'arbre genealògic. Cada família té la seva pròpia memòria col-lectiva a la qual tots els seus membres estan connectats i tenen accés (Jodorowsky, 2015).

\section{Sisena acció}

Proposta del futur: com m'imagino en un futur?

Activitat proposada:

Un dibuix, una imatge, una paraula, un poema, un petit escrit, la línia de la vida...

Acció, creació... Creem futur, imaginem, creem. Tot un món de possibilitats a les nostres mans.

\section{Reflexions sobre aquesta proposta:}

Amit Goswani, professor de física a la Universitat d'Oregon, durant el Congrés de Consciència Quàntica celebrat a Madrid el 2015, parlava dels nous descobriments de la física quàntica. Segons ell, el comportament de les micropartícules canvia depenent del que fa l'observador: "Quan l'observador mira, es comporta com una ona; quan no ho fa, com una partícula."

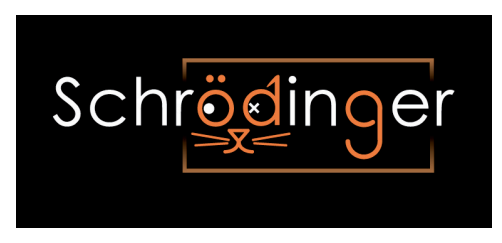

Això vol dir que les expectatives de l'observador influeixen en la realitat dels laboratoris... i cada un de nosaltres està compost de milions d'àtoms. Nosaltres creem la realitat? Els nostres pensaments afecten aquesta realitat? (Lipton, 2005; Garnier, 2012). Ens seguim fent preguntes...

\section{Conclusions}

Aquest projecte permet treballar els fonaments bàsics de l'educació sistèmica i dur-los a la pràctica des d'un treball de descoberta personal on els alumnes són els protagonistes, agafant el paper d'investigadors i historiadors amb la collaboració de les famílies, un dels objectius primordials de l'educació sistèmica. D’aquesta manera s'estableix un pont ferm entre l'escola i la família.

S'aborda el concepte de pertinença al grup, el treball d'agraïment i valoració de tot el llegat familiar, la mirada amorosa cap a tot el que ens ha fet ser com som, amb les nostres individualitats $\mathrm{i}$ característiques.

Mitjançant activitats creatives i artístiques es van treballant totes les competències bàsiques i ampliant el coneixement d'altres cultures i de mapes familiars.

És un treball on les emocions es van mostrant i desplegant amb molta delicadesa $\mathrm{i}$ amorositat $\mathrm{i}$ s'aprofundeix en sentiments que de vegades són difícils de treballar a l'aula.

El projecte ha afirmat i consolidat el sentiment de grup de pertànyer a un clan i s'ha creat una dinàmica en la qual és més fàcil solucionar els petits conflictes del dia a dia. Recordant que som tots una tribu, que formem part d'un sistema que cal cuidar en el qual amb les nostres diferencies trobem punts de semblança amb els altres, reafirmem el concepte que tots tenim un lloc i que tots els orígens i cultures són igual de dignes.

\section{Referències bibliogràfiques}

Arntz, W.; Chasse, B. i Vicente, M. [dirs.] (2004). “¿iY tú qué sabes!?» [En línia]. [Data de consulta: 18-02-2015]. <https://www.youtube.com/watch?v=yw5Q9-YbFjY>.

Bailón Trueba, F. (2015). Los inuit, cazadores del Gran Norte. Barcelona: Nova Casa Editorial.

Cordero, M. (2012). Manual práctico de pedagogia sistémica: Un itinerario para introducir la mirada sistémica en el aula. México: Grupo CUDEC.

GARDNER, H. (2011). Inteligencias múltiples: la teoría en la práctica. Barcelona: Paidós. 
Garnier Malet, J.P. i L. (2012). El Doble...¿cómo funciona? Madrid: Editorial Reconocerse.

Hellinger, B. (2008). Los órdenes de la ayuda. Buenos Aires: Alma Lepik.

Jodoroswky, A. (2015). "La teoría de los campos mórficos de Rupert Sheldrake y el árbol genealógico." [En línia]. Plano sin fin [Data de consulta: 23-01-2015]. <http://planosinfin. com/la-teoria-de-los-campos-morficos-derupert-sheldrake-y-el-arbol-genealogico $>$.

La Moneda, A. (2010). Vivir, sobrevivir. El genograma, un mapa familiar. Mèxic: Grupo CUDEC.

Lipton, B.H. (2005). La biología de la creencia. Madrid: Palmyra.

Phanem, T. La canción de las personas [En línia]. [Data de consulta: 12-02-2015]. <https:// docs.google.com/presentation/d/1OTE1Llm OaMRvJFDPIKmuiiwlOX50onn0HD3ekH WINXU/edit\#slide $=\mathrm{id} . \mathrm{i0}>$.

Marquier, A. (2010). El maestro del corazón. Barcelona: Luciérnaga.

Morin, E. (2002). Los siete saberes necesarios para la educación del futuro. Barcelona: Paidós.
Rodrigo de la Casa, A. (2012). "Danza, emoción y pensamiento" [En línia]. Síneris. Revista de música, 1. [Data de consulta: 07-022015]. <http://www.sineris.es/danza.html>.

Sheldrake R. (2009). Morphic Resonance. The Nature of Formative Causation. Vermont: Inner Traditions/Bear.

Traveset, M. i Parellada, C. (2014a). La xarxa amorosa per educar. Les idees clau de la pedagogia sistèmica multidimensional. Barcelona: Octaedro.

Traveset, M. i Parellada, C. (2014b). R-Evolució del sistema educatiu. La pedagogia sistèmica multidimensional, un paradigma educatiu emergent. Barcelona: Octaedro.

Traveset, M. (2007). Pedagogía sistémica. Fundamentos y práctica. Barcelona: Graó.

Traveset, M. (2014). Pensar amb el cor, sentir amb la ment. Recursos didàctics d'educació sistèmica multidimensional. Barcelona: Octaedro.

Watzalawick, P. (2003). ¿Es real la realidad? Confusión, desinformación, comunicación. Barcelona: Herder. 